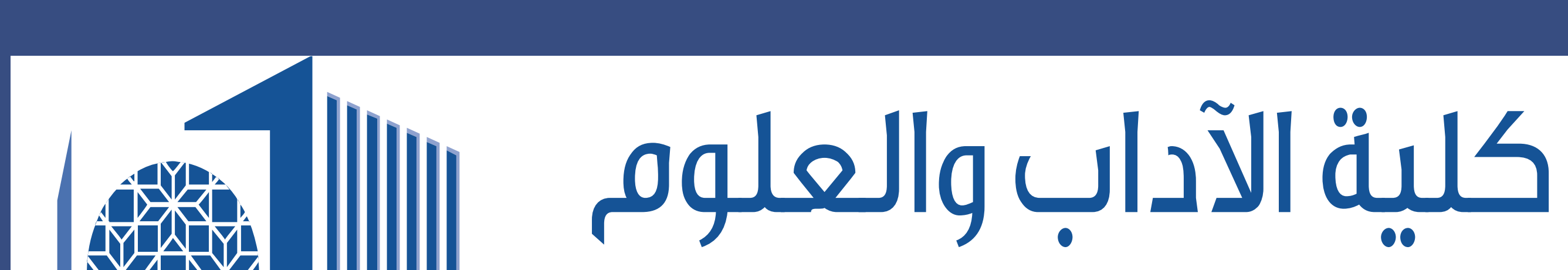
College of Arts and Sciences QATAR UNIVERSITY حاهeة

\section{Approaches to achieve sustainable use and management of groundwater resources in Qatar}

Ayesha Ahmad and Mohammad A. Al-Ghouti Qatar University, Department of Biological and Environmental Science

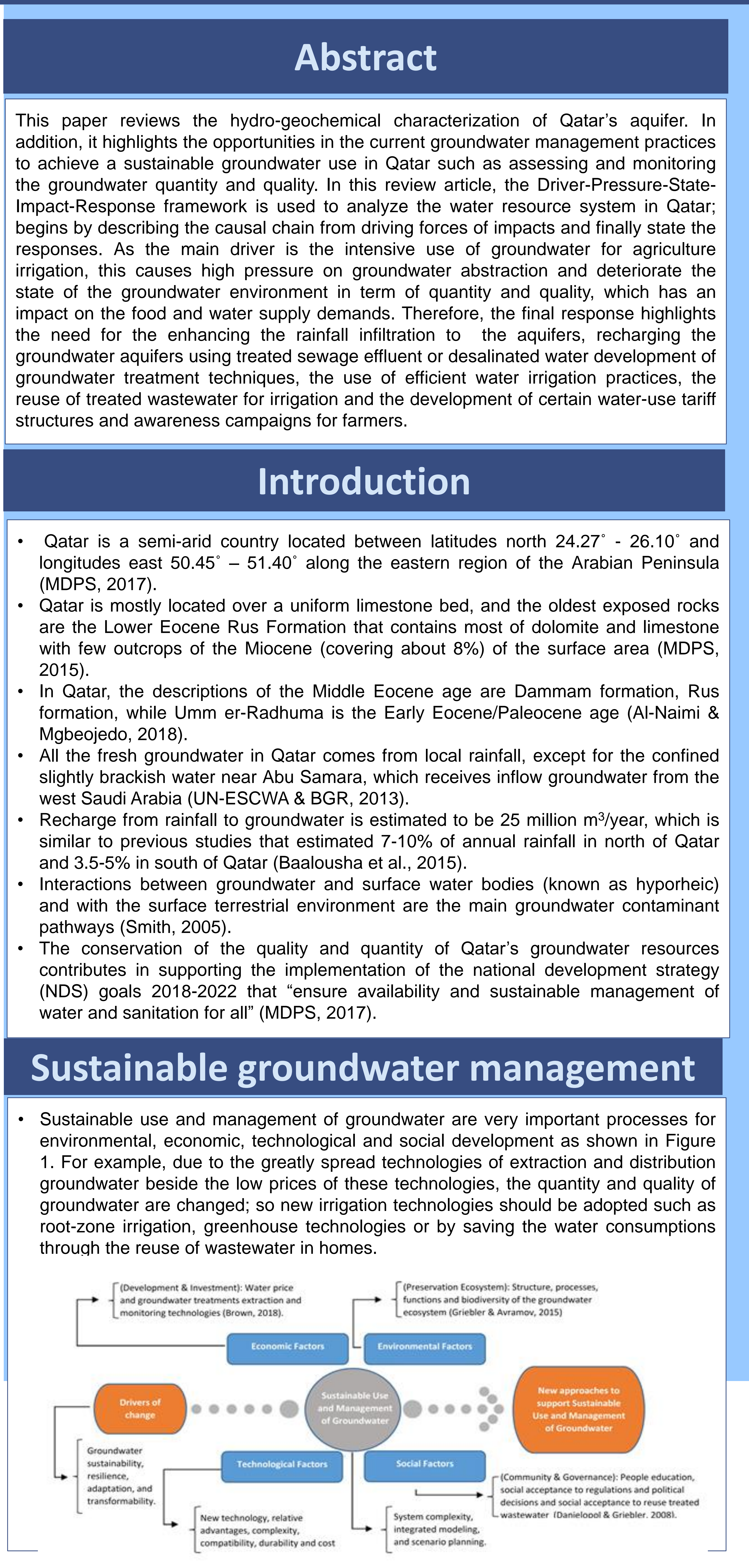

Types of groundwater

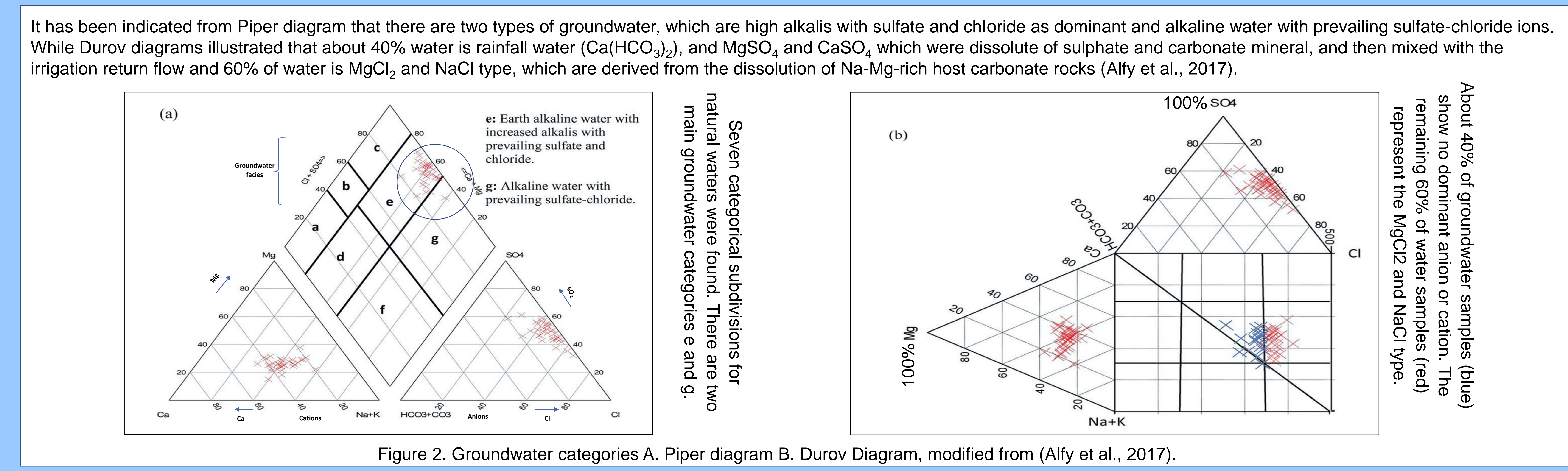

Groundwater treatment, modelling and GIS mapping

\section{Groundwater treatment}

Qatar has recently undertaken the challenge to become the moss self-reliant and sustainable country
the Middle Eastern region. Today, in Qatar, groundwater is the major renewable water resource comprising around 47.5 million m3/year. Groundwater abstraction is 30 times higher than average
recharge rates this has led to a dramatic drop in groundwater table and the increase in salinity (Water
Stharisics 2015 .

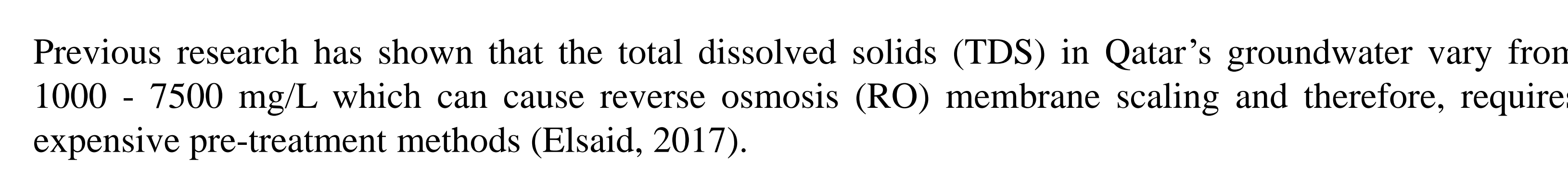
Our preliminary results have also shown that the quality of groundwater is deteriorated, and several
contaninants including toxic metals and metalloids are exceeding permissible limits. Boron (B), lithium

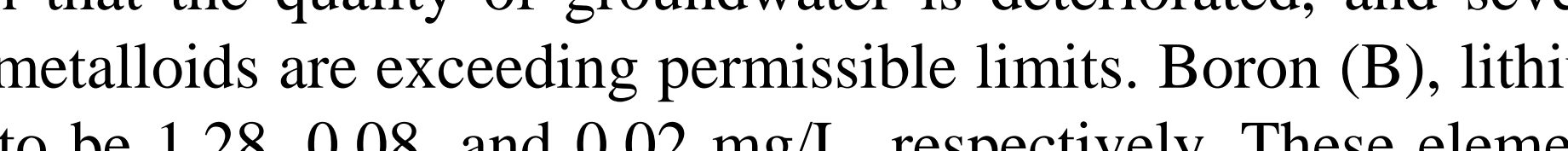

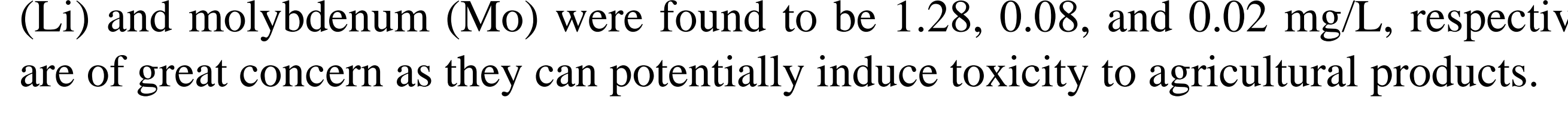

it is essential to develop novel treatment approaches
improve the quality of these water sources in Qatar.

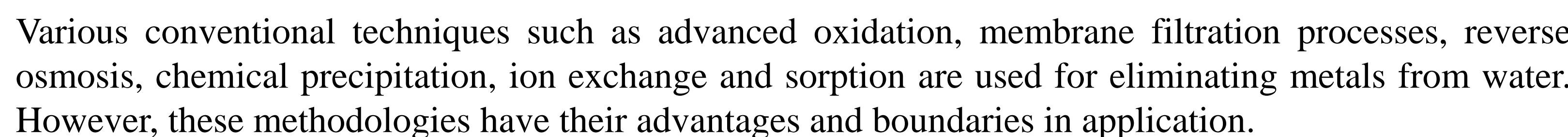

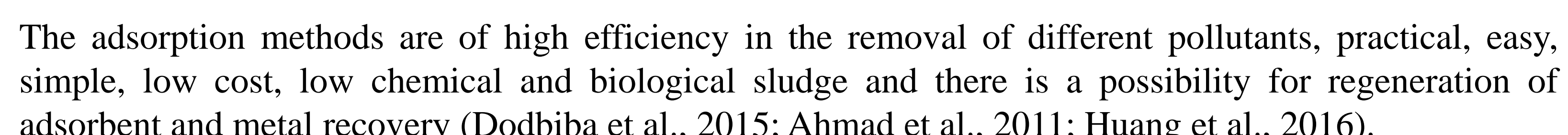
The non-conventional adsorbent such as natural material sorbents are of extensive source,
enviromentally friendly and low cost. Sucth has clay, cellulosic materials such as agriciultural wastes,
sludge and fly ash from industrial by product (Guane tal



Figure 3. Maps generated for A. molybdenum, B. boron concentrations in Qatar's groundwater
using the interpolation technique.
DPSIR framework for groundwate resources management

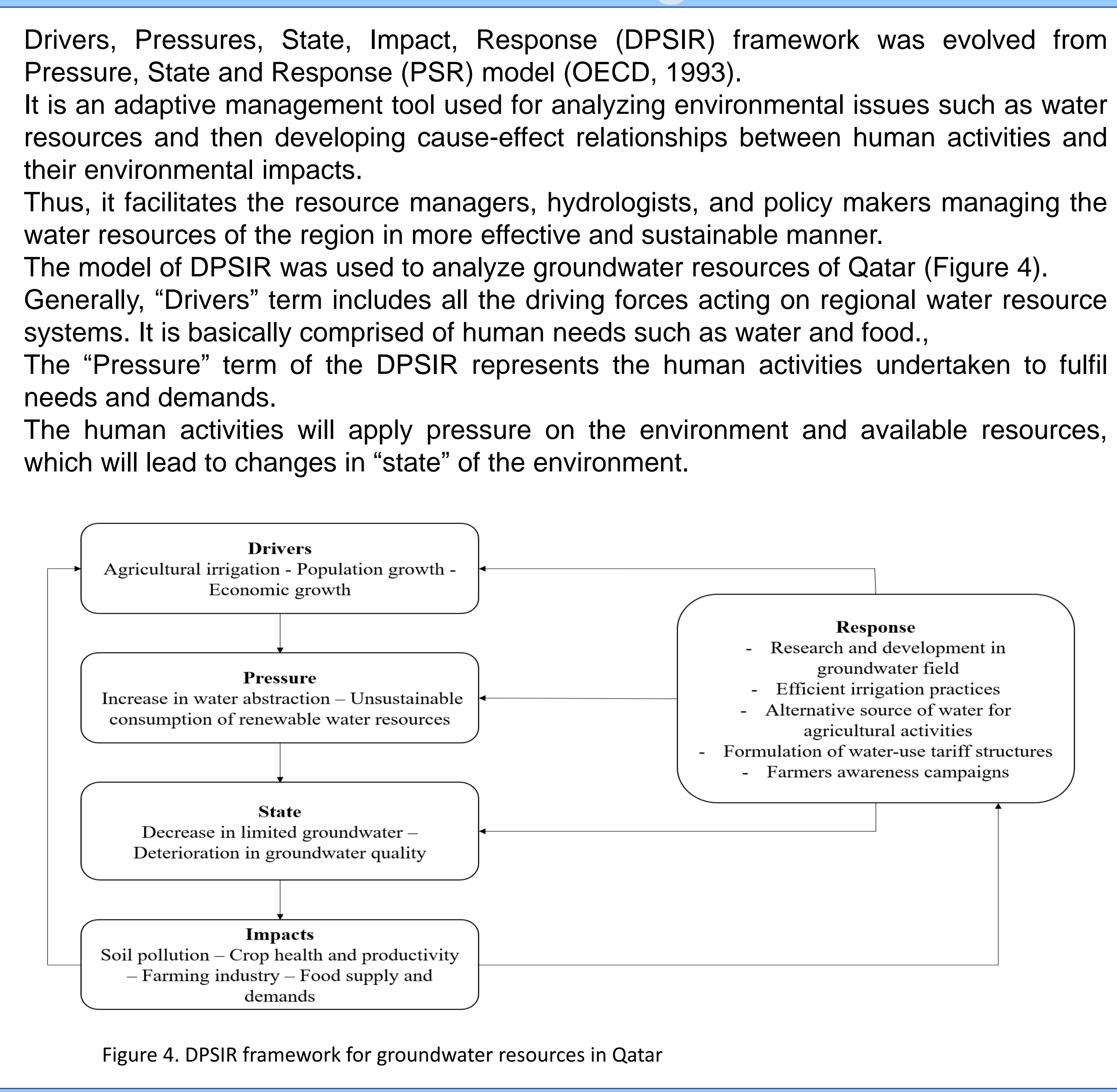

Conclusions

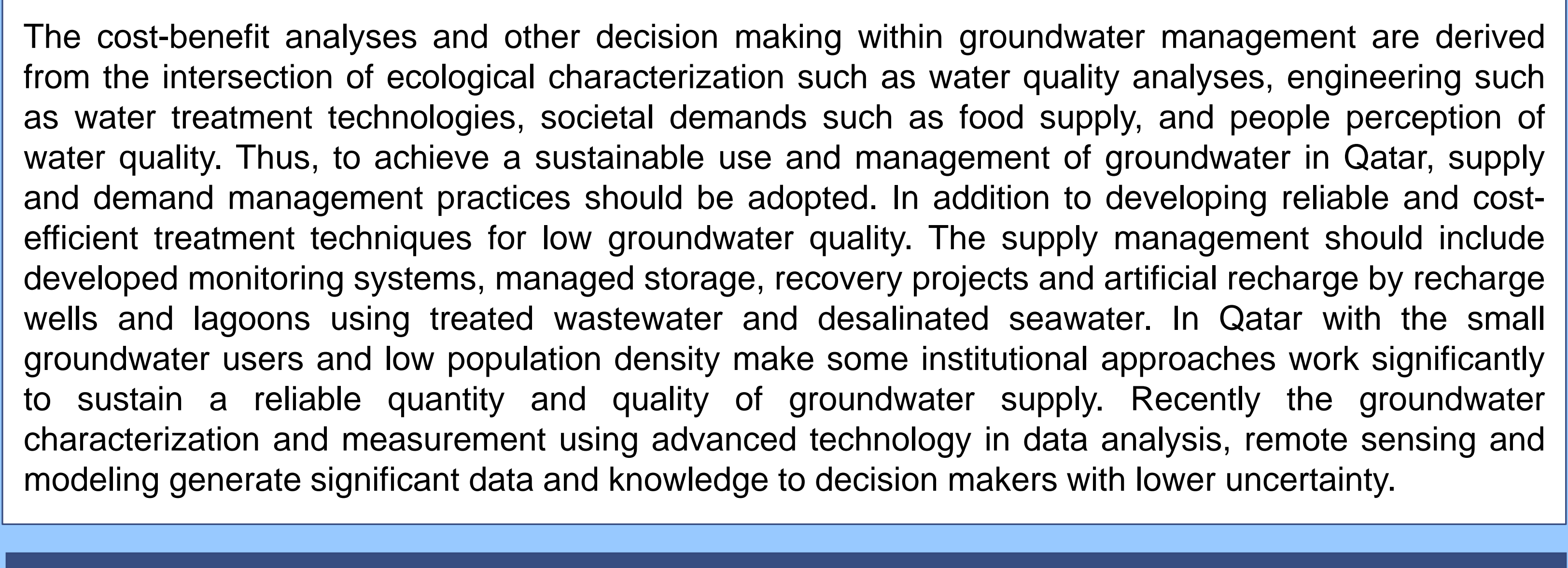

Acknowledgement

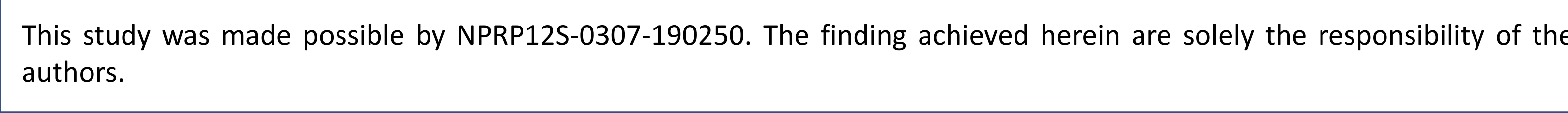

Reference

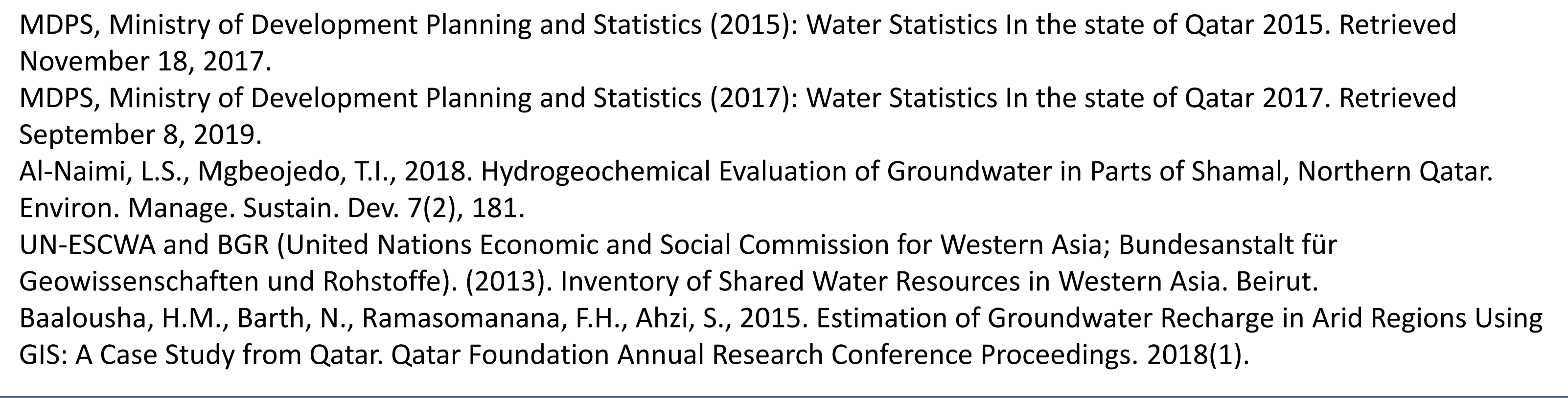

